\title{
El teatro tradicional catalán de los siglos XVII al XIX
}

\author{
JuLIA Butiñá
}

$U N E D$. Académica de la RABLB, correspondiente en Madrid

A través de una obra hagiográfica inédita de cada siglo vamos a intentar distinguir los rasgos principales de este teatro; a su vez, desde este ángulo, trazaremos alguna conexión con el teatro profano, motivo por el cual nos referiremos al teatro tradicional y no exclusivamente al religioso.

El género hagiográfico, como parte importante del religioso y asimismo por su fuerza y volumen dentro del teatro tradicional, ya estaba definido en la etapa medieval como un teatro primitivo y hierático. Si va a pervivir a lo largo del tiempo, en el curso de estos siglos, es a causa de dos notas esenciales: su impermeabilidad y su popularidad. Destacamos también de antemano otro rasgo propio de este teatro que nos permitirán ver las obras que aportamos: su imbricación a una realidad comarcal, característica que es aneja al carácter local de los textos. Desde este último enfoque interesa concretar que las obras que veremos aquí pertenecen al norte de Gerona: al siglo XVII, la Comèdia de santa Quitèria; al XVIII, la Comèdia de sant Julià $i$ santa Basilisa, y al XIX, la de san Martirián, que constituye el epígono del género.

Este material nuevo no nos va a revelar ninguna obra maestra ni ofrecer conclusiones innovadoras, sino que confirmará lo que la crítica ya había establecido. Sin embargo, a través de estas tres obras catalanas, plenamente típicas, comprobaremos algunos rasgos propios de este teatro. Veremos, pues, el proceso del teatro popular, de la Edad Media a la Renaixença.

Este género presenta ricas connotaciones desde otras perspectivas más allá de la estrictamente literaria, pues obliga a exceder del valor textual estricto y comentar aspectos escenográficos y sociológicos. Así como es importante para el estudio de la historia de la lengua, que en este caso es rico testimonio del catalán coloquial. Aspectos, sin embargo, que veremos de una manera más que resumida, selectiva, a modo de ilustración o ejemplo, pues a través de estas obras salpicaremos una serie de datos de interés diverso sobre el género. 
Hay que partir en primer lugar de la perspectiva general que sitúa el género hagiográfico catalán de estos siglos, continuación del medieval, en la dinámica de las literaturas occidentales; ello equivale a decir que - como ocurre principalmente en las tierras hispánicas - se mantiene a lo largo de estos siglos de un modo marginal - mejor que paralelo- al desarrollo del teatro culto.

Conviene tener en cuenta este panorama tan amplio y firme como homologado, que ofrece a menudo isoglosas con otras literaturas - de aquí su interés en estudiarlo conjuntamente en diversas lenguas- porque nos hace conscientes de la limitación que supone concentrarse en un ámbito concreto.

Si el drama litúrgico había nacido en la Edad Media al calor de las catedrales y las abadías, por cuyo esplendor rivalizaban, lo que ya denominamos en estos siglos teatro hagiográfico vive alrededor de las fiestas, como la de Corpus en las ciudades, o bien las patronales en el entorno rural. A fin de valorar debidamente su peso y significado hay que tener presente que en la época barroca se promoverá un fuerte dinamismo de la vida comarcal; además, es la época por antonomasia de todo lo que sea fiesta.

Ceñiremos un poco la ambientación de los siglos XVII y XVIII, al cual pertenecen nuestros manuscritos. Desde el punto de vista literario hay que decir que es el período constituido por los que vamos a llamar siglos de plata de la literatura culta catalana. Es el tiempo de dependencia hacia la cultura central, dependencia que afecta igualmente a las otras literaturas españolas no castellanas y que testimonia bien la castellanización lingüística y estética (Ribera, 1989). Ahora bien, si es la etapa en que brota la diglosia, conviene advertir que a la vez irá germinando la Renaixença. Es decir, mientras que la expresión se deja influir por la castellana y sus formas literarias, entonces en momento de fuerte empuje creativo y de ascendencia social y cultural, irá arraigando un fuerte clímax de interés y aprecio hacia las fórmulas que caracterizan la identidad del pueblo: hacia la lengua, hacia los géneros populares, hacia las instituciones y la historia. Una explicación simplista pero válida de este fenómeno responde al enfoque de la sociedad por capas: se dio un abandono de la conservación de identidad por parte de la clase alta, a la vez que se daba una resistencia y un reforzamiento en el pueblo. Como protagonista de esta función de conservación de la identidad cultural está la literatura popular. Y en ella, en primera fila: el teatro.

Ello tiene una interesante y curiosa consecuencia desde una perspectiva de la sociología: pues el beatus ille de las gentes que hacen y asisten a estas funciones a lo largo de estos siglos, aunque desaparezca bajo el progreso, arrasado por un siglo XIX de pretensiones modernas e industriales, constituirá el futuro ideal restaurador. Aquella vida rememorada como idílica será el desiderátum de la Renaixença, del renacer romántico catalán. Por lo tanto, hay que 
valorar en mucho el papel del pueblo en la continuidad cultural catalana; es decir, si en los siglos de oro --los medievales - predominaba la literatura culta, en éstos lo hará la tradicional.

Es una etapa difícil desde el ángulo socio-económico. Sacudida por agitaciones sociales, que explotarán a final del siglo XVIII, por ejemplo, con los llamados "rebomboris del pa" (1789), y carcomida por los hechos bélicos: de la $\mathrm{Paz}$ de los Pirineos (1659) en adelante, enlazamos con la Guerra de los Ocho Años (1689-1697) y la de Sucesión (1702-1714), para acabar con la Guerra de la Independencia, llamada en Cataluña la Guerra Gran, ésta ya a principios del XIX, lo cual redondearán las tres guerras carlistas. Valga como pequeña muestra de cómo fue especialmente perjudicial para las comarcas casi fronterizas, como es la zona en la que se sitúan nuestras obras, al norte de Gerona, un testimonio de la primera de las guerras citadas, y que es una prueba fehaciente de cómo les llegaba a afectar el paso de los ejércitos:

"s'emportaven molt blat, lo qual donaven an als cavalls, que era terror, y per las casas no dexaven res, finestres ni portes" (Constans, 1951).

A pesar de todo, a grandes rasgos, se suele considerar que el campo catalán, en el siglo XVII se rehace en silencio de la crisis del XVI, así como en el XVIII ya se inicia el resurgimiento comercial y demográfico. Retengamos, pues, estos dos datos: la inestabilidad política y el incipiente y progresivo resurgir económico, como notas del ámbito agrario.

En cuanto a los movimientos culturales, hay que decir que es tal la arrolladora estabilidad de este género que apenas se trasluce su influencia; tan sólo se puede apreciar la huella del Barroco, debido a la abundancia de su fasto y el empuje efervescente. Así pues, la oratoria de lucimiento, culterana y conceptista, según la moda castellana bien asentada ya a finales del siglo XVII, alcanza incluso la zona catalana de más allá de los Pirineos, la llamada Catalunya Nord.

Ahora bien, aunque a este influjo parecen corresponder ciertos rasgos, es de delicada distinción en qué grado un elemento concreto, como el mismo gracioso, tiene ascendencia castellana o bien tiene una deuda para con el hedonismo de la tradición popular, el deseo de agradar al público, manifiesto en este teatro desde que se despoja de los oficios divinos. O bien hasta qué punto es auténticamente barroca $\longrightarrow$ también propia del gusto vulgar, como veremos aquí- la típica mezcla de lo más sutil con la deformación grotesca.

Pero si cuesta reconocer las huellas barrocas en el compacto y arcaico género dramático religioso, por mucho que se trate del llamado siglo de las pelucas, no podremos ni intuir el frívolo rococó, ni la llustración, ni las corrientes iluministas de la literatura catalana entre el Barroco y el Romanticismo. Hasta el punto que el influjo neoclásico, de raíces tan hondas francesas, y que 
deja preciosas muestras en el teatro culto, no es sensible en el tradicional de Catalunya Nord hasta una fecha tan tardía como 1770. Tampoco pretendamos encontrar reflejo de movimientos como el jansenismo, generales en Europa y sensibles en otras manifestaciones literarias, como por ejemplo se advierten en el terreno pedagógico en obras procedentes de la misma zona gerundense.

Para acentuar esta impenetrabilidad recordemos que, en cuanto a técnica teatral, estamos en la época de Marivaux y de Goldoni, y que en cuanto a ideología estamos en el corazón de la producción de un Voltaire y que en 1751 aparece el primer volumen de la Enciclopedia. Hitos que convienen para flanquear el continuismo de este teatro que permaneció impermeable, que se detuvo en estado arcaizante. La explicación es que la misma sociedad se mantenía muy cercana a los orígenes: "molts actes devocionals i de pietat del XVIII són idèntics $o$, almenys, semblants als que foren causa del naixement del teatre; per això no té res d'estrany que perduri l'antic costum de representar la Passió i les escenes del Naixement (...) i que fins i tot hom escrigui peces sobre aquests temes, tot procurant adaptar-les als motllos tradicionals" (Comas, 1972). Es decir, era una sociedad compacta, muy sensible a los viejos parámetros culturales.

Por ello, a la altura de esos siglos, se sentía una auténtica fascinación por la vida y aventuras de los mártires. Si la exageración de las virtudes hasta el punto de quedar desvirtuados los personajes era normal en la narrativa medieval, como bien muestran relatos como el Valter e Griselda, aquí se llega a una folklorización de la fe cristiana, que reproducía como arquetipos a los santos; éstos, en rigor, son simples estructuras cargadas de significado ideológico. Además, los santos de la literatura popular eran un objeto de ritual y un cuerpo con poderes, de quien se obtendrá protección, sea para algo específico, una enfermedad concreta, sea de un modo general como un favoritismo para con aquel pueblo (Courcelles, 1986). Los estudios de los bolandistas nos permiten comprobar que esto no sólo era general en todas partes, sino en los diversos géneros literarios y está en consonancia con la obsesión por las reliquias, como es propio de una religión más ritual que propiamente espiritual y se extiende mucho más allá de la Edad Media en la cual se originó.

Tras haber situado el género en las coordenadas históricas y culturales hay que hacerlo en la producción literaria catalana. Observemos que los tres ámbitos, poesía, prosa y teatro, presentan un campo de interrelaciones entre la producción culta y la popular: en las memorias - que se dan en todo el dominio linguístico y que paradójicamente se mantienen también impasibles ante la historia porque reflejan la intrahistoria repetida y entrañable-, en los gozos -composición religiosa cantada que deriva de un género trovadoresco- y en el teatro hagiográfico. Los gozos religiosos también tienen una acentuada vida comarcal y están ligados a nuestro género, pues los santos que ellos cantan son los familiares, los que otorgan favores, los de interés local. ¿Cómo podemos observar en estos géneros el fenómeno del contacto culto-popular?: cuando nos quedan vestigios de un autor con cierta cultura, sea en el talante, en ciertos 
vocablos o en una métrica cuidada, que en los gozos manifiesta una nueva redacción o en las obras teatrales, una refundición o la mano de un copista.

A las notas peculiares del viejo teatro hagiográfico durante esta etapa se añaden, de acuerdo con la impronta de los cánones de la comedia castellana, elementos concretos como la división en tres jornadas o las escenas de galanteo. Son importantes también dos tendencias que se acusan del siglo XVI en adelante y que distinguen estos dramas de los medievales: desaparece la típica concisión y aparece la comicidad. Esta última nota, como fruto que es de una usurpación vulgarizante del terreno reservado a la Iglesia, estará muy ligada a la didáctica y condicionada religiosamente. Pero hasta tal punto se convertirá en algo esencial que se ha considerado que cuando está ausente es por falta de habilidad del autor en el conocimiento psicológico del público y de las masas.

En cuanto a las fuentes observemos también una gradación, ya que si estas obras en sus inicios se fundamentaban en la liturgia oficial, progresivamente se irán empapando de fuentes ligadas a las costumbres, y beberán de la liturgia popular, como por ejemplo los gozos citados.

Asimismo se ha establecido una sutil diferenciación a partir del siglo XVI, en función a que a partir de entonces se recicla el elemento sobrenatural en términos de verosimilitud; o sea que el determinante del prodigio ya es el poder o voluntad del hombre; y esto nos llevaría a plantearnos hasta qué punto - a pesar de hallarnos ante reminiscencias medievales-, ya hay un proyecto escénico que responde a un nuevo destinatario (Quirante, 1989). En nuestras obras apreciaremos también la progresión: si la primera viene determinada por los avisos angélicos, en la segunda son los protagonistas los que deciden su porvenir.

A veces también se aprecia en esta época el factor alegórico - aunque ya había hecho presencia en consuetas mallorquinas del siglo XV-, favorecido desde la Reforma por la eficacia de la imagen, pero especialmente gracias a la potente figura de Calderón, que se representó a lo largo de todo el XVIII en ciudades como Barcelona o Valencia. Su sombra se supone que se extendería, en gran parte vehiculada por los comediantes ambulantes, hasta alcanzar el teatro que se realizaba en la calle.

Si nos ceñimos a la zona de Gerona que nos interesa hay que tener en cuenta que nos hallamos en un sector especialmente propicio para el cultivo de esta manifestación teatral, ya que su cultura está asentada desde la etapa de los primitivos monasterios, y de ella proceden clérigos influyentes en la sociedad dieciochesca. Zona, pues, a la que el poso cultural primitivo no ha seguido un vacío.

Una visión retrospectiva desde el siglo XIX, nos patentiza la fuerza del hecho teatral como exponente de una tradición. Pues ese arraigo nos lo atesti- 
gua, no sólo el estudioso del teatro gerundense por excelencia en esa época, Girbal, sino también las estadísticas, que muestran que en 1863 Gerona es la sexta provincia de España en número de locales. Concretamente en Bañolas población alrededor de la cual giran nuestros manuscritos-, a mediados de siglo, había una Societat Teatral y un teatro estable de 450 plazas (lo que, sobre una población inferior a los 5.000 hab., arroja, aproximadamente, una cifra tan elevada como una plaza por cada 10 habitantes; Martínez Quintanilla, 1865).

El primer manuscrito que trataremos proviene de finales del siglo XVII. Hay que advertir que de este siglo conocemos muy pocas piezas hagiográficas; Romeu (1957) tan sólo cita una mallorquina sobre san Cristóbal y la de santa Bárbara, de autor conocido, Vicent Garcia, el famoso rector de Vallfogona. Josep Sebastià Pons (1929), que estudia el teatro hagiográfico del Rosellón de este par de siglos sólo cita un total de cuatro obras. Hay que tener en cuenta de todos modos que ello no es índice de su inexistencia pues, debido al hecho de la oralidad, es más bien excepcional la conservación de los manuscritos.

Se trata de una pieza sobre santa Quiteria, la defensora de las enfermedades contagiosas y de una manera específica, de la rabia (todavía hoy se comen en la zona unas típicas empanadillas con señales de los dientes). Tiene dedicada una ermita en Sant Martí de Campmajor, que ya se documenta en la segunda mitad del siglo IX como posesión del monasterio de Bañolas. Aquel pequeño agregado, que depende de la parroquia de Sant Miquel de Campmajor, cerca y al nordeste de Bañolas - nos interesa el trazo comarcal-, a mediados del siglo XIX, contaba con 27 casas dispersas y 8 agrupadas, con un total de 219 habitantes. Conviene tomar nota de que en 1654 hubo una fuerte epidemia de peste que afectó a todo el valle de Campmajor, suceso que muy bien pudo haber estado ligado a la génesis de nuestra obra.

No he encontrado ninguna referencia de otra pieza de santa Quiteria en lengua catalana. Sólo una Relació de la vida de santa Quitèria, aproximadamente un siglo posterior, de 1787, que Rubió califica ya de estilo moderno.

El manuscrito, encuadernado en piel, ha perdido las cubiertas y está prácticamente completo. Le falta la página que llevaría el título y el inicio del prólogo, así como posiblemente la última con algún verso. Comprende 156 páginas, de lectura sin problemas y de la misma mano, excepto de la página 81 a la 84 , donde se hace evidente un enlace distinto y defectuoso.

Empezaremos por las fuentes, normalmente para estas obras, además de los gozos, el Flos Sanctorum o Leyenda dorada de Jacopo de Vorágine, del siglo XIII, que contiene las vidas de los santos del calendario eclesiástico, y que nuestra obra sigue con estricta fidelidad desde la 2. jornada. Los gozos correspondientes a santa Quiteria se pueden hallar en varias comarcas, pero 
observaremos con especial interés tres modelos recogidos en su comarca de Bañolas. Todos ellos con un mismo texto - si bien los más modernos han añadido una estrofa-, se cantan en Sant Martí de Campmajor. Hay aún una versión diferente, recogida en el Maestrazgo, en el País Valenciano, que por su estilo narrativo es más próxima al romancero, como bien muestran estas estrofas:

"Té lo rei de Portugal nou filles com una plata; totes nasqueren d'un part, d'un part de la reina Càlsia.

La més bella de les nou n'era la que el rei amava; la més bella de les nou Quitèria s'anomenava."

Estos gozos valencianos son muy interesantes para nuestra pieza puesto que nos ofrecen datos, como por ejemplo que la santa tuviese ocho hermanas, que no constaban en los gozos de la comarca ni en la leyenda áurea. La leyenda dorada, sin embargo, nos da el nombre de su padre, Catèlio, de quien no se dice el país, sino tan sólo que era pagano. $\mathrm{O}$ sea que nos encontramos con un caso de superposición de la vía hagiográfica y de la popular, la cual proporcionará todo el inicio de la obra dramática, de tono muy legendario. Este añadido referente a los orígenes de la santa precede las dos partes habituales en este género: la que acostumbra a incluir la conversión, milagros y apostolado, y la de la pasión y muerte.

Como muestra de estas obras, de las que puede considerarse bastante representativa, daremos una sinopsis de la acción: la reina Càlsia, que ha tenido nueve hijas de golpe en un parto, está horrorizada por la posible reacción del marido. En situación tan apurada se deja aconsejar por Satanás y ordena a Centina que ahogue a las criaturas en el río. (En este pasaje podríamos reconocer cierto eco bíblico, que es fácil de explicar contando con que estas obras sedimentan mitos ancestrales y que ya en una Passió del siglo XIV se había reconocido el mito de Edipo tras la figura de Judas.)

La lucha interior de Centina, a consecuencia del rechazo a cumplir una orden tan bestial, da pie a la introducción del elemento alegórico, pues dialogará con la Memoria, el Entendimiento y la Voluntad, que aquí se denominan "las Virtudes". De golpe, Catèlio, el rey y padre de las criaturas, tropieza con el ama Centina, quien, en medio de tan terrible ataque a su conciencia, toda temblorosa, no dudará en exponerle los hechos. Catèlio, decidido, hace venir otra ama, Éncia, a quien encargará la crianza de las niñas que iba a ahogar Centina.

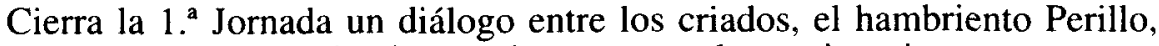
que hace de gracioso, y Llamina; se dan promesa de matrimonio, pero no apreciamos los que serán habituales elementos de cortejo. 
En la 2. Jornada un ángel indica a Quitèria, que lógicamente es una de las nueve niñas que ya se ha hecho mayor, el lugar donde ha de dedicarse a la contemplación —el monte Oria; Orio en el manuscrito-. Como dice la rúbrica "en la part més acomodada del catafal se gurniran alguns rams, com si fore una montanya, que la santa si quedarà." Esta Jornada también tiene incrustados elementos alegóricos: ahora Santa Fe y el Mundo, que discuten juntos, ya que ambos quieren influir en la santa y, a través de ello, están sirviendo para instruir al público en la doctrina.

Finaliza la Jornada con un tono dramático, porque Càlcia añora fuertemente a su hija, lo cual manifiesta un sin sentido - como también puede extrañar que no llore en las restantes - o bien la pérdida de algún pasaje. Después de una escena de arrepentimiento y perdón se propone recobrarla, pero resulta que nadie le da razón de su paradero. Este pasaje contiene una clara incoherencia, porque el ama que responde aquí de Quitèria es Centina, quien tenía encargado el crimen, lo cual nos delata que la escena de Éncia, la mujer a quien se las confió Catèlio debe ser un añadido posterior que ha quedado inconexo. Por lo tanto, al igual que la sucesión de hermanas, es una muestra flagrante de la superposición de los elementos novelescos que ya hemos indicado, o bien falta algún fragmento que redondeara el argumento. Lo que sí se hace evidente es que nos hallamos ante una crasa refundición.

Encabeza la 3. Jornada el encuentro de Quitèria con sus padres, puesto que ya ha vuelto a su casa por medio de un nuevo aviso angélico. En seguida se planea su boda con Germano, el mayordomo de palacio. Pero Quitèria por medio de otra comunicación angélica recibe ahora orden de irse a una ciudad llamada Aufràgia, a donde se dirigirá acompañada de los buenos y simpáticos criados. A poco de llegar allí, el presidente Lentiano promulga un bando contra los cristianos. Quitèria entonces, tras haber superado los maléficos planteamientos de la insidiosa Carn, la Carne, vestida de rojo, y a cargo de quien corre la parte alegórica de esta Jornada, consigue convertir al idólatra de una manera fulminante con una sucinta exposición de la Redención.

Enterado de todo ello su padre, Catèlio, y temeroso de que el emperador le haga responsable, envía a Germano, el prometido de Quitèria, a fin de que la haga volver o en otro caso le dé muerte allí mismo. El desenlace difiere algo según las fuentes: en los gozos de la comarca pasa primero por el suplicio del fuego y en los valencianos se cita una fuente que brota en el lugar donde cae su cuerpo. Nuestra obra sigue fielmente aquí el Flos Sanctorum, donde directamente con una máxima economía de tormentos, Germano le corta la cabeza, la cual coge la santa hasta llegar a la ciudad de Adimense (Andunense en la obra teatral), donde tenía que ser enterrada. Los primeros gozos especifican en dos versos un grave acontecimiento: "dividida la garganta parlàreu, o rara cosa!", y además el número de pasos que anduvo con la cabeza entre las manos: novecientos. 
Haremos algún breve comentario acerca de los personajes. Uno para llamar la atención sobre el hecho de que Lucifer y Satanás estén desdoblados, lo cual aparece también en otras obras, como en el portuguès Auto do Dia do Juizo o en la tragedia rosellonesa de las santas Justa y Rufina. El último, privado del primero. como suele ocurrir y según el efecto cómico que se pretendía, sale disfrazado, en este caso de mujer, aunque - según la rúbrica- "aportarà unas banyas ques vejan".

La crueldad de los padres de la mártir, hecho muy normal que provoca el aumento de su mérito y el efecto de compasión hacia ella, también la sufrirá por ejemplo santa Tecla - en un manuscrito que también se ha conservado en la comarca y que he editado recientemente-, y asimismo la observamos en una de las pocas piezas hagiográficas del Códice de Autos Viejos castellano, en la de santa Bárbara (s. XVI).

El último comentario que haremos es destacar la viveza del personaje del gracioso, como es lógico absolutamente grosero a la vez que de una gran inocencia. Su importancia se hace patente en el hecho de que nos muestre de vez en cuando su intimidad, rasgo que generalmente es exclusivo o se reserva a los santos. Perillo es también quien utiliza la lengua más rica, hasta el punto de que nos ha permitido confeccionar ricos vocabularios por campos semánticos; quizá el más rico sea el de los improperios (se publica en el artículo en prensa). Queda claro que aunque su figura proviene del Renacimiento castellano y que ya figuraba en las comedias de santos, el gracioso es el personaje que mejor se adapta y refleja los gustos del pueblo. Buen comilón, cualidad quizás acentuada por influjo barroco, pues el exceso de comer es típico del carnaval, se nos muestra en expresiones próximo a los personajes de otro teatro popular religioso, los pastores del ciclo de Navidad, muy bien identificado con la literatura popular. Como bien advertía Rubió (1984-86), la parte más interesante del teatro catalán de esta época es la parte más popularizante.

En cuanto a los temas, destaco uno de vieja tradición y propio del caudal profano, como es la crítica hacia los médicos, a través de una muy divertida emulación de un análisis de orina por parte de Perillo, y otro de nuevo estilo, como es que se acuse el querer casar a la gente forzadamente, de lo cual se lamenta también la santa Tecla recién citada de la misma zona. (Hay que resaltar la posible novedad de este tema desde el punto de vista literario, si tenemos en cuenta que a El sí de las niñas, de 1806, todavía le faltaba más de un siglo.)

Otro aspecto, finalmente, nos llevará a hablar de la escenografía. Me refiero a la cefaloforía, esto es el motivo literario de la decapitación, propio de la hagiografía, y que aparece ya en una de las pasiones más antiguas, la Passio Iusti, del siglo VII. Este hecho se adjudica a casi un $75 \%$ de los màrtires, incluso a algunos que no fueron decapitados, sencillamente porque aunque hayan superado otros tormentos no hay duda de que esto es lo que asegura la muerte definitiva. Y no solamente era drástico sino que además era 
muy ennoblecedor. (Podemos hacer un inciso para comentar que el tema de la decapitación, con otro contexto pero con efectos igualmente ennoblecedores y con relación posiblemente en su origen, se da también en la literatura caballeresca, concretamente en la narrativa francesa; Riquer, 1989). Y no extraña que en el caso de nuestra santa sea un elemento de peso, cuando he localizado una referencia literaria, del tránsito al siglo XIII, en una famosa composición del trovador Raimbaut de Vaqueiras que dice en un verso: "Ni peu cap Santa Quiteria". Por ello, no debe extrañarnos que conste en el manuscrito por dos veces el hecho de recoger su cabeza del suelo, pues o bien responde a una insistencia dada la gravedad del caso o bien traduce un error muy sintomático.

De aquí pasamos a tratar de la tramoya, tan importante cuando el hecho de reproducir la ilusión de la realidad era un factor clave para encandilar al público. Aquí la decapitación no se nos explica, porque, dado su éxito ya desde las piezas medievales, había recursos para ello: en la comedia de Judit se decía que se tenía que hacer una cabeza igual para Olofernes y cuando se decapitaba a san Crispí o san Cristòfol se aclara que los actores son substituidos por maniquíes. En cambio, se hacen sabrosas aclaraciones para el intento de ahogar a las recién nacidas: "en faran fer duas ho més que sian de guix ho altre cosa, per poderles enseñar quant convinga".

Sin ser exclusivo de esta obra resalta la frecuente caracterización de los personajes mediante gestos y vestuario. Se indican bien los movimientos de los personajes por medio de gestos estereotipados. Así Lucifer, que sale dando botes y saltos, cuando no encuentra a Quitèria, para indicar su irritación picará con los pies, de un modo parecido a como he detectado en piezas inglesas (Lascombes, 1989). O la santa, que acostumbra a salir muy devota, alguna vez se refrega los ojos "com qui plora". En cuanto a los objetos, vemos que la criada Llamina sale "ab un axugamans per devantal" y "arremangada de braços"; Perillo con diferentes herramientas que lo definen, como una azada al hombro, o con "un cànter que sya buyt, sens aigua". De un ángel se nos dice que lleva "una tovallola o mocador de seda, que sia net, y sobra un pa, que sia molt blanch". Es muy oportuno para una santa adaptada a su época que, aunque en una mano lleve los rosarios, en la otra lleve un abanico - cuando sabemos del furor que hacían estos instrumentos en la Barcelona del setecientos-.

El hecho de haber un solo catafalco, a pesar de que se señalan dos puertas y la cortina, que hacía siempre de telón de fondo, la alinea entre las obras que Romeu define de transición respecto a las medievales, que eran de representación panorámica. Aquí los diferentes espacios van seguidos en el tiempo y se indican diferenciados, como ocurre con el oratorio de la santa o como vimos con el bosque, lo cual simplifica mucho el escenario, si bien ello no implica una merma de solemnidad. Bien testimonian ésta los ángeles, guerreros por su vitualla, y que, "rodella i espasa en mà", flanquean algunas escenas, o bien que el ángel de la guarda con una palma en una mano y una corona en la otra, seguido por la santa con la cabeza en las suyas, vayan girando en torno al catafalco, 
lo cual tenía lugar dos o tres veces consecutivas, muy despacio, mientras que el primero cantaba un salmo en latín.

La métrica, aparte de alguna pequeña variación, como fragmentos en codoladas - es decir, combinación de versos cortos y largos-, sigue la muy frecuente cuarteta heptasilábica cruzada $a b b a$, en teoría consonante pero en realidad con muy numerosas asonancias. Observemos de todos modos alguna estrofa en que los versos 1 y 4 son octosílabos, la medida por excelencia de la dramàtica medieval:

\author{
"En lo mont Orio se espozàran \\ que jo mateix ho sentí, \\ y de mas orellas ohí \\ quant esposos se anomenàran".
}

En estos versos queremos llamar la atención a la ayuda indicativa del acento para indicar el pretérito indefinido (perfet en catalán) y distinguirlo así del futuro, de igual grafía.

También encontramos la dislocación del acento:
"Li sien intercessors
en donar-li un feliz part
alegre y regozitjat, que pugam alegrarnos",

lo cual, lógicamente, era normal en el tiempo en que se cantaban.

Estos puntos de la métrica, junto con la rima fácil y las frecuentes irregularidades, parecen indicar para esta pieza un origen antiguo, que ratificarían algunos errores, como que Jesús sude en "lo ort de Gericó", o bien que se diga en el prólogo que és "nova representació".

Sin embargo, y a pesar de esta ascendencia, otros elementos parecen renacentistas y barrocos, como los seis personajes alegóricos. Ahora bien, éstos, incrustados en una obra eminentemente popular, no tienen punto de comparación con los de una obra barroca de planta, hagiográfia también, como es la Comèdia famosa de la Verge y màrtir santa Bàrbara del Rector de Vallfogona, en la que salen ninfas y todo. No hay tampoco una exposición de la cultura de la Contrarreforma, con la eclesialización que le es propia, como tampoco vemos huellas de conceptismo, motivo por el cual no podemos calificarla entre el auto sacramental y la representación medieval, como se ha hecho con la consueta del hijo pródigo (finales del siglo XVI). Pues tanto desde el punto de vista ideológico como del literario predomina la simplicidad. 
No hay ni que exponer los argumentos de los demonios, por un estilo de inocentes. El armazón de la obra es medieval, a pesar de que se haya revestido superficialmente de ciertos tonos abarrocados a fin de hacer alguna concesión a la moda. Pero estos elementos están plenamente integrados en la dinámica popular y conjugan con el factor còmico, como muestra clarísimamente Perillo al avisar que ha llegado la Carn:

"Míria, senyora Quitèria, que li demànan audiència, y és unia senyora galan que la anoménan la carn. Vaja y luego sens tardar que bona serà per sopar."

Esta comicidad tan ingenua como fresca y viva, que entre otras salidas parecidas nos dice que un muerto, de tan estirado, parece "diputat posat en cadira", nos da quizá la primera nota de la comedia. Al enfrentarla con la obra citada de Vicent Garcia, que no sería muy anterior, también se nos hace manifiesto el contraste, porque aunque el criado salga allí con una retahíla de insultos no resultaba un humor natural ni consiguientemente popular como el nuestro.

Linguísticamente se sitúa en el catalán oriental, el de la zona donde se ha conservado el manuscrito. En cuanto a onomástica interesan especialmente los nombres añadidos a las fuentes. Entre ellos observemos el pintoresquismo de la comitiva de los criados que acompañan a Quitèria: Genibera, Catasio, Fulciano o Dromerico y sobre todo el de Bocacio (escrito tanto con $c$ como con $s$ ), y que en buena lógica del certaldés sólo tiene la coincidencia de los fonemas. Si la tendencia principal es a los nombres acabados en -o, lo cual indicaría influjo del castellano, vemos que a veces acaban también con $-e$ o con $-i$, y que son generalmente estrafalarios. Por tanto, responden a un afán de exotismo o a gusto por la broma. Actitudes para las cuales era idónea la terminación castellana como conocida pero foránea. Igualmente en la pieza de san Julià gerundense veremos Malfi, Saldoni o Tambrico y en la rosellonesa, Benavencio, Flaudino, Abderiano, Bari, Calife, Zurrere..., que parecen confirmar lo que proponemos.

Desde el punto de vista léxico es muy interesante por conservar vocablos que no constan en los diccionarios hasta mucho más tarde (merdicer), por ser posiblemente invención del copista (mirapixat) e incluso por documentar un hápax: carxena (vocablo sólo registrado antes en Muntaner).

La lengua delata, pues, que nos hallamos ante una obra antigua que ha sobrevivido pasando por diversas manos, lo cual habíamos concluido ya del análisis literario. 
La otra pieza hagiogràfica, por el hecho de estar firmada y de contar con otros testimonios literarios de la misma mano, nos permitirá ya hablar de autor. Ahora bien. hay que considerar dos cosas: en primer lugar, que es un autor de payés, calificativo que, sin connotación despectiva, hay que añadir, a fin de reafirmar que a pesar de la autoría nos seguimos moviendo en un terreno eminentemente popular y que se trata de una producción que aunque no sea anónima sigue siendo rural. Por otro lado, aunque sea poco común, no se ha de valorar excesivamente el hecho de contar con tal nombre o con otras obras suyas, puesto que el conjunto de esta producción de proyección local, lo que tiene de más valioso, como bien dice Jordi Carbonell (1977), es precisamente lo que tiene de carácter unitario.

El manuscrito de la Comèdia famosa dels esposos sant Julià i santa Basilisa se conserva completo, en bastante buen estado: consta de 171 páginas y 45 personajes, y es una obra más larga y compleja que la anterior que hemos visto. Tiene una curiosa datación interna, antes de la Sexta y última Parte: "vuy 31 d'octubre 1751". Y una final: "de la mano y pluma de Narcís Collell, abitant en lo molí den Camps de Sant Andreu de Altorn; vuy dia 5 de janer de l'any del Senyor de 1752" (Como el manuscrito anterior, se conserva en can Butinyà).

Conviene referimos ahora al entorno comarcal del denominado actualmente Pla de l'Estany; advertimos - al oeste de Bañolas, la capital-que Sant Miquel de Campmajor —el lugar de santa Quitèria - está muy cerca de El Torn, donde vive Narcís Collell, nuestro presente autor; y cerca, también. Villademuls, Ollers, y Galliners, de los que hablaremos seguidamente. La parroquia de Sant Andreu del Torn, que depende del monasterio de Sant Pere de Besalú, ya está documentada en el año 977 (Monsalvatje, 1910), y dentro de su demarcación se encuentra el santuario del Collell, el más importante de la diócesis. Monasterio que hay que resaltar que coincide con el apellido del autor. (Quizá sea oportuno recordar, en cuanto a la tradición teatral de este sector, que en esta misma parroquia de Sant Andreu del Torn se encontró el más antiguo canto de la Sibila que se conoce, datado hacia 1260).

La población, a mediados del siglo XIX, vivía en sus cuatro quintas partes diseminada. Y los molinos, que ya se aprovechaban desde la época medieval para hierro o harina, se encuentran hoy a ambos lados del río Ser. Todo ello parece dibujar un círculo comarcal de raíces antiguas.

Es curioso sin embargo que el santo que se celebra, san Julià, sea el titular de Galliners, agregado del municipio de Vilademuls, aproximadamente a unos $25 \mathrm{~km}$. El autor cita además a "sant Baldiri, patró nostre", es decir, otro santo el cual tenía dedicado un santuario en las afueras de aquella población, del cual se conservan aún las ruinas. No sabemos qué relación podía tener aquel habitante de un molino de El Torn con estos pueblos cercanos, pero lo que se hace evidente es que nos movemos en un círculo con vínculos naturales. 
Hay que insistir en que no pretendemos destacar una zona por sí misma porque a fin de cuentas su valor deriva de la cohesión genérica como hemos dicho, pero este aspecto nos permite resaltar como muestra o modelo un hecho general en este teatro: que responde a una manifiesta realidad comarcal. Este factor tiene una importancia vital en su génesis y propagación. Quizá sea oportuno citar aquí el caso de un bretón muy prolífico, que también firmaba sus obras, Jean Conan, algo posterior -ya del siglo XIX-, quien hace una relación de sus viajes, los cuales describen un claro entorno comarcal, con distancias no superiores a ocho leguas (Le Braz, 1981). Es lógico que el hecho sea general y tiene su explicación: en buena lógica, a la tarea de preparación se correspondía la de difusión. Y este teatro, como se daba en medio de una población agraria y dispersa, requería de los medios de comunicación al alcance del pueblo: los mismos vecinos y los mercados.

De todos modos no se puede aplicar el criterio de una manera drástica: junto a estos manuscritos se hallaba el de santa Tecla y ésta, aunque aparece entre los santos del arca gótica más preciada en la comarca (Constans, 1947), es una santa forastera. Tecla es la santa por excelencia del área de Tarragona, lo cual no excluye que se le haya hecho una obra en otra zona o bien que el manuscrito haya remontado hacia áreas más septentrionales, especialmente si se trata de una santa, como ésta, de gran fama. O sea que el índice comarcal es eso: un índice a tener en cuenta.

Volviendo a san Julià es un santo muy común en Cataluña, al igual que lo es en Francia; sólo en los alrededores de Bañolas cuento varios topònimos (Sant Julià de Marlant, Sant Julià del Mont y Sant Julià d'Ordis). Pero hay que tener presente que hay diversos Julianes; el nuestro, de procedencia oriental, quizás egipcio, no parece muy común: no coincide con ninguno de los cuatro que recogen las Vides de sants rossellonesses, uno de los textos hagiográficos más antiguos y valiosos catalanes, ni creo que lo sea el que cita el Dictionnaire des mystères de Migne, en una mención de 1735 , porque no se cita a su compañera, santa Basilisa. En las fuentes litúrgicas españolas también hay confusionismo y los Julianes son asimismo de difícil precisión. No extraña con todo lo dicho que la Leyenda dorada lo catalogue entre los santos extravagantes. Sin embargo, del mismo san Julià veremos dos versiones dramáticas más en la zona francesa, una en la vasca y otra en la catalana, rosellonesa.

De esta santa pareja he conseguido información diversa. Por un lado, tenemos información referente a su culto, que en España, de donde pasaría a Francia, es muy antiguo, incluso puede provenir del siglo VI. Por otro lado, una relación de seis hojas en latín (manuscrito 10 de la Biblioteca Universitaria de Barcelona), que sigue muy de cerca el Flos Sanctorum, firmada en 1553 por Michael Llobera, de su cofradía, que reunía merceros, guanteros, gente de pasamanería, etc. Lo que nos remite a otro rasgo peculiar de este teatro: su vinculación a los gremios. 
Según es habitual la obra sigue fielmente la leyenda dorada, con pequeñas variaciones de tipo cronológico en el curso de los acontecimientos. Especialmente en función a su originalidad, por protagonizar la santa biografía un matrimonio, daremos unos breves trazos argumentales del comienzo: los padres de Julià, según consta, ilustre familia de Antioquía, en Siria, pero bajo la clara ideología correspondiente a la institución catalana del hereu, quieren que su hijo, ya mayor, de 18 años, y a fin de asegurar la descendencia, se case. Pero él, dado que pretendía consagrarse a Dios, les pide un plazo de reflexión. Jesucristo, en una aparición, deshará el conflicto, pues le asegura que a pesar del matrimonio, no perderá la virginidad. Así pues, accede a su boda con la joven Basilisa.

Al llegar la noche de bodas, su habitación se llena de aromas exquisitos, fenómeno odorífero común a toda la literatura hagiográfica en momentos excelsos. Entonces Basilisa, la novia, manifiesta su extrañeza, ya que no era primavera ni había razón para tales perfumes; Julià le explica entonces que el motivo es su castidad, virtud que entonces ella revela también amar. Ante esta situación, en el mismo tálamo nupcial harán los dos voto de virginidad. Poco después mueren los padres y ellos se separan a fin de fundar conventos, que consiguen gran esplendor. Pronto, al final de la II Jornada, morirá también Basilisa, advirtiendo antes a Julià de su martirio, el cual ocupa cuatro Jornadas, es decir el resto de la obra.

La persecución sigue las líneas consabidas: los diálogos con los persecutores se aprovechan para exponer la doctrina, así como tiene lugar una larga retahíla de milagros; como por ejemplo, sanar el ojo del que le estaba martirizando, resucitar un muerto, convertir a la misma familia de los perseguidores, y en resumidas cuentas - como siempre- el santo supera toda clase de tormentos hasta que al final es degollado. Quizás interese aquí hacer un inciso para considerar cómo desde la teoría y sociología de la comunicación, y sobre todo gracias a las series de televisión actuales, nos podemos explicar hoy el gusto por lo idéntico, por medio de la combinación de la estrategia de la variación (Salvador, 1989-90).

Daremos un vistazo a los personajes. Choca en primer lugar el nombre de una criada: Eneyda, que no podemos en esta fecha, en que aún no contamos con obras catalanas neoclásicas, ni mucho menos en este contexto, relacionar con la obra latina; pero sí hay que considerar que el gramático bañolense Ullastra parece que tradujo la Eneida al catalán en una fecha muy próxima, el 1743. De lo cual muy bien podía tener conocimiento nuestro Narcís Collell, de la misma comarca y por aquel entonces estudiante. Sea como fuere este nombre nos remite nuevamente a la voluntad de exotismo que ya habíamos mencionado y podríamos parangonarla con el criado de la pieza anterior que se llamaba Bocacio. Así como hay que tomar nota del dato de la formación humanística propia de estos autores, y que también atestiguan las piezas profanas (en el mallorquín Entremès dels sagristans burlats se cita a Virgilio). 
El gracioso destaca por la comicidad que denominamos escatológica, a veces casi obscena, lo cual nos llevaría a preguntarnos si es un eco del Rector de Vallfogona, autor de renombre precisamente por su agudeza y brillo en este tipo de bromas, de gusto también muy quevedesco. Y si se ha dicho que esta figura tiene el papel de enlazar con el público, aquí es un hecho, pues sus bastas alocuciones, generalmente dirigidas a las mujeres, enmarcan las divisiones de la obra. Baste como muestra que en el momento más sublime, después del martirio, diga que hay que hacer un hoyo para las cabezas de los mártires porque de otro modo "la pudor nos matará a tots", cuando muy al contrario -y además de la asimilación ya aludida "bondad moral/perfume" - el síntoma por antonomasia de los despojos era el buen olor.

Otro personaje, el enamorado de Basilisa, Credoto, que no tiene apenas papel y parece ser un añadido a fin de dar ocasión a que se luzca un cantante con su guitarra - pues se especifica que se cantan los versos y que canta bien-, nos lleva a establecer otra nota de la obra: que parece escrita expresamente para un ámbito concreto, y en un código no sólo restringido, sino muy específico. Así parecen indicarlo las alusiones a hechos tan puntuales como que cite a un tal "mussèn Miró", a los zapateros de Galliners, o a un maestro de gramática, que —como veremos- podía ser él mismo.

Las bromas se mantienen con bastante inocencia, como es común, y con exclusión - al menos aparente - de toda sombra de erotismo. Las escenas que podrían rozar este aspecto se han revestido de una estilización ideal, como también confirmamos con ocasión de desnudarse santa Tecla antes del martirio. Otra cosa es que en la realidad - conociendo y comprobando en este mismo teatro el gusto popular- - se hicieran bromas, lo cual contribuiría a explicar el desfase entre los textos conservados, respetuosos y devotos, y las sucesivas y tajantes prohibiciones por parte de la Iglesia. Que la risa debía flotar es un hecho; no olvidemos que se trataba de un espectáculo. Pero en el texto aparece sólo un deseo de idealización artística, expresamente acentuado en la escenografía de la noche de bodas: el lecho ha de ser lo más bello que se pueda (aunque la expresión es normal en este teatro). Interesa en este sentido hacer alguna comparación, porque observamos que en el Flos Sanctorum, los héroes se levantan de la cama para rezar, mientras que aquí están al lado de la cama, y que en una obra rosellonesa posterior ya están arrodillados en dos reclinatorios, objeto poco apropiado para una cámara nupcial. Ello nos da una referencia interesante: el dato erótico se obvía expresa y progresivamente.

En consonancia con este rasgo idealizador observemos la utilización de la imagen bíblica del ciervo herido:

"Així com lo siervo ferit vinch corrent y asedegat, perquè $a b$ la aygua del vostre baptisme sia jo del tot rentat." 
Es de las pocas imágenes de la obra, pero se repite por tres veces, lo cual abunda en esta inocente voluntad de estilo dignificado, y a la vez constata que nos hallamos ante un autor de pocos recursos, que acude en ocasiones a comparaciones muy socorridas (el padre dice a Julià que él es concha y el hijo la perla, o uno la leche y el otro la nata).

Pasando al aspecto escenográfico hay que resaltar los muy importantes efectos que reclamaban tan brillantes martirios. Aunque el fuego se representaba desde mucho tiempo atrás, así como se usaba la pólvora, es un estímulo para nuestra imaginación actual la rúbrica que dice que cuando retablo, ídolos y sacerdotes paganos caen al infierno, sale una gran humareda, se hunde el templo y han de salir llamas de fuego. Es de lamentar que no tengamos explicaciones de la que indica que, tras la degollación, se mueve un gran terremoto, cuando otras rúbricas son más explícitas: "los pòsan estopes als dits y pòsan foch en ellas, apartats, del modo que nos púgan cremar", o bien esta otra: "coménsan a escorxar lo cap a sant Julià y a Celso, y aquí se ha de fer una tremoya com si fos pell". Recordemos una nota esencial de este teatro: el deseo de fundir el elemento realista con el maravilloso.

Y junto al desiderátum de realismo no podemos relegar el factor del candor del público. Ya en la mallorquina Passió de sant Jordi, del siglo XV, hablaba el dios Apolo; y aquí también los dioses falsos hablan aunque sea para decir que no tienen ningún poder.

En cuanto a la métrica, presenta tendencia a la asonancia en los versos pares y a la medida de 7 sílabas; es decir, son de voluntad romanceada. Pero la rima y el cómputo silábico son muy deficientes:

"Ja sé que esta vida

som viadors, jo ja ho veitg,

y que a esta estam per hostes,

surtim quant menos pensam".

La rima, prácticamente inexistente, y que nos hace diagnosticar una gran inexperiencia y no como en otros casos de este teatro una métrica corrompida que hubiera servido de cañamazo, forzosamente había de dar lugar a la improvisación. Las irregularidades alternan con las erratas muy variadas de tipo formal; lo cual lleva a formular errores conceptuales, como podemos ver en los siguientes versos, en que dice Jesucristo:

$$
\begin{aligned}
& \text { "obeheix a ton pare y mare } \\
& \text { que permaneixéran sempre verges". }
\end{aligned}
$$

y donde la $a$ y la $n$ claríssimas no permiten ninguna otra lectura más que el pretérito o bien -más incongruente aún- el futuro. Así pues, la predominante dejadez provoca todo tipo de desmanes, desde trastocar letras a recurrir a repeticiones o descolocar versos. 
Desde el punto de vista lingüístico también confirmamos los rasgos literarios: un grado más intenso que en la obra anterior en cuanto a vulgarismos y adaptación muy diversa de toda clase de barbarismos. Ahora bien, una libreta de estudios conservada de este autor nos permite distinguir en algunos casos que los castellanismos son propios de este teatro y quizás también del afán ennoblecedor de su lenguaje, pues emplea aquí limpiar y en la libreta -como traducción de frases latinas- correctamente la forma catalana netejar. Usa, pues, limpiar para indicar "dejar limpio al máximo", como intensificación de netejar, lo cual incluso hoy es un barbarismo utilizado.

Para este punto de la invasión léxica a la que es tan propicia este teatro y que se intenta explicar desde muy distintos puntos de vista, interesa poner de lado algún caso similar. Vemos que en el teatro bretón, por medio de este género se dio el mayor afrancesamiento léxico de Bretaña (Le Braz, 1981). O sea que este teatro se nos muestra como notable vía de asentamiento de barbarismos.

De Narcís Collell tenemos algunos datos (Butinyà, 1993): autor de payès por su talante y poco miramiento intelectual, vemos que sin embargo muestra un cierto conocimiento de la literatura bíblica o de la clásica. Nos confirma este relativo nivel cultural la mencionada libreta en que practicaba sus estudios de latín y que nos deja entrever las gramáticas con que estudiaba. Este cuaderno, que cosió posiblemente él mismo, contiene ejercicios de traducción del catalán al latín a lo largo de 4 años (de 1740 a 1744); la letra y la complicación sintáctica manifiestan también el progreso. Son una serie de frases que, como dice, les hace el maestro, para que las traduzcan de varias maneras. No tiene valor literario, pero es un interesante complemento sociológico: alude a la espinosa convivencia de militares y campesinos - de lo que hicimos mención al principio-, refleja costumbres de la época —como la educación con castigos físicos o cuando el correo llega al pueblo- y no falta alguna escena propia de la picaresca estudiantil. Al principio dice que está estudiando (estudiaba en un colegio barcelonés y de los jesuitas: Cordelles), y según parece desprenderse de uno de los últimos ejemplos ejerce él mismo el magisterio, lo cual nos permitiría pensar que era un maestro quien pocos años después escribía la obra hagiográfica. Ello es congruente con lo que observa Le Braz en el teatro bretón: que si en un primer momento los autores fueron clérigos, después siguieron los "cloërs", ex-seminaristas y los maestros de escuela. Tendríamos aquí, pues, un caso bastante puro de estos anónimos autores del teatro popular, que manifestaban un cierto grado de formación o estaban rudimentariamente avezados e inclinados a las letras.

Nos acentúa el perfil de su figura otra obra de la que también es autor Collell, y a la que hemos de referirnos, aunque sea de una manera marginal. Se trata de una obra del teatro profano y de gusto también popular: el Entremès del Ball dels ermitans, editada en 1991. La autoría la delata sin confusión la letra además de una serie de indicios, como la conservación conjunta de los manuscritos, lengua, papel, etc. 
La obra, a pesar del descuido formal, que también acusaba la de san Julià, responde típicamente al gusto de un hombre de letras, a quien agradan los juegos de palabras divertidos y fáciles y que malsabe latín. Hijo, pues, de un ambiente popular pero con cierta formación.

Está igualmente datada al final de la pieza, en el año 1753; o sea, el año siguiente de la obra hagiográfica. El Entremès del Ball dels ermitans sigue las líneas de este género, que si inicialmente adornaba las comedias, se independizó con vida propia. El tema, de burla clerical, es muy característico: el galanteo a una dama por parte de unos ermitaños - personaje forzoso equivalente del sacristán en los entremeses castellanos- que presumen de cultos y que rivalizan con unos personajes, pastores en este caso, más rudos que ellos. Asimismo es viejo y difundido mediante los sainetes cervantinos el tema: la duda entre el amor y el interés.

Como en muchos entremeses - también en el ya citado mallorquín Entremès dels sagristans burlats y como en el teatro popular castellano y según recomendaba Lope de Vega en el Arte nuevo de hacer comedias - entre los recursos cómicos figura el elemento lingüístico, que aquí utiliza cuatro lenguas: además del catalán, el castellano, un medio francés-occitano y el ya anunciado latín. Éste con la carga cómica típica de parodia eclesiástica; el castellano, en boca de un caballero que pide que no le hablen en catalán porque lo entiende mal, y el semifrancés, hablado por el "gavatxó" - manera de designar despectivamente en catalán a los franceses-, continuamente ridiculizado y que no entiende nada de catalán. (Observo un punto de contacto con las farsas vascas, en las que el castellano es empleado por los demonios o personajes sin relieve: Urkizu, 1989; aquí lo hablan los capellanes en ocasiones en que son objeto de burla.)

Destaquemos el personaje que hace de bobo -deuda típica hacia el entremés castellano-, el cual se llama Arlequín, deuda pues ahora para con la Comedia del Arte, que ya se percibe en estas letras y géneros desde el siglo XVI. También desde este siglo se acababa el teatro profano con el ball y la rodona, y no con las típicas garrotadas. (Advertimos de no confundirlos con los balls de la zona de Tarragona.) Los versos del final confirman que todo era una excusa festiva, pues se pretende

"dar-vos gust y alegria no fent offensa a Déu".

La broma pues era inocente - reparemos además que en este caso la mujer cortejada es soltera y no hay marido ofendido-. Pero una serie de excusas en la despedida nos revelan claramente el deseo de justificación:

"Encara que indessent, podria estar provada que en altres pobles honrats se és fet pùblicament". 
El teatro profano, género diferente al objetivo de nuestro estudio, nos afecta por presentar con él múltiples coincidencias, hasta el punto de haberse llegado a hablar de una profunda osmosis. Se da muy acusadamente en la lengua y también en los temas y en los personajes (como bien expresa el mismo título del libro de Rainer Hess: El drama religioso y romántico como comedia religiosa y profana, obra en que se estudia a fondo este contacto a través de las literaturas de cuatro países de la Romania). En nuestro caso lo confirmamos desde la catalana y además entre los puntos de enlace añadimos el hecho de que sea un mismo autor quien, según viniese al caso. escribiese una pieza para celebrar al patrono u otra para divertir a la gente. Ambas finalidades iban muy ligadas, como habíamos anticipado, desde que el teatro religioso se impregnó de intención lúdica, supeditada siempre sin embargo a la didáctica.

Del mismo siglo XVIII conozco, gracias al prof. Urkizu, otra pieza dramática en lengua vasca, publicada en 1891 en Burdeos, titulada: Saint Julien d'Antioche. Se define como pastoral, es decir drama rústico representado con el ceremonial tradicional, en este caso por los campesinos de la Soule, cantones de Mauleón y Tardets, o sea que nos seguimos situando en una zona relativamente pirenaica. Parecen lógicas en principio ciertas afinidades y divergencias que se observan, pues si el argumento es prácticamente cl mismo, los nombres de los personajes secundarios varían. Apreciamos que cn las obras de san Julián de la zona francesa aparecen demonios pero no en la catalana, y que, así como en la rosellonesa (a la que nos referimos seguidamente) abundan los galicismos léxicos. aquí vemos entre los objetos de tortura el makhila. denominación del bastón vasco de madera con una punta a modo de aguijón para guiar a los bueyes y con un puño de plomo forrado de cuero. Parece por todos los aspectos enunciados que no nos hallamos ante tres versiones de un mismo texto, sino ante tres obras diferentes.

Enlazamos con otra obra en catalán y de una zona vecina. del Rosellón, y también sobre estos dos santos: Martiri de san Julià y santa Baselici. No podemos dar ninguna conclusión en cuanto al posible nexo con la obra de Collell, pues no hay ninguna pista para establecer el contacto, si bien es fácil suponerlo dada la proximidad geográfica. Lo que sí se desprende ya a primera vista es que ambos autores han seguido directamente la fuente hagiográfica.

De esta obra rosellonesa se conservan dos manuscritos, uno se halla en el monasterio de Cuixà, firmado con las siglas A.D.B., que es a su vez copia de 1861 de la obra original de François Comes, escrita en 1813 en El Soler — pueblecito rosellonés de donde también el santo matrimonio era patrón-. A pesar de que nos hallemos también ante un cierto rastro de autoría, recordemos que no se trata del concepto de creación, sino de una plástica escénica didáctica. que nos remite a un terreno mixto de hibridismo, según se da a veces en estos géneros, y en que autor y receptor se confunden.

Comparativamente con la obra gerundense de san Julià, la rima está más cuidada, aunque también es visual (hace rimar cantúria con el imperfecto 
venia), tal como es normal en este teatro; y otra diferencia métrica la hallamos en la proximidad de ésta al alejandrino, pues los versos - generalmente pareados-- suelen ser muy largos. Se indican a menudo cantos litúrgicos, algunos de los cuales, como Alma laudes, eran propios de estas piezas desde la Edad Media.

Si en la obra de Collell hemos aludido a la riqueza de efectismos, ésta, que dobla en extensión a aquélla, debía constituir un lucido espectáculo.

Esta obra. aunque tiene aproximadamente el mismo número de páginas que la anterior, decimos que la dobla en extensión a causa del tamaño de sus hojas. Es algo sabido la tremenda duración de estas obras, que van creciendo con el tiempo en incisos y añadidos; y si para aquélla había calculado una duración de unas seis horas, la de ésta es muy considerable. La representación duraba desde la tarde hasta la mañana siguiente (solamente la loa o prólogo duraba una hora). Acudían familias enteras, que mientras cenaban y, al menos los niños, dormían. Nos testimonia todo ello un historiador provenzal, Henry, que asistió a su representación alrededor de 1823. Como era de esperar su actitud fue duramente crítica, tanto por la desmesurada extensión como a causa de su mentalidad, muy lejana ya de aquella reliquia ancestral. El erudito provenzal no sólo recomienda que, por ser más educativo $-\mathrm{y}$ he aquí otro factor siempre vivo en este teatro - se represente en su lugar a Racine sino que pide la intervención del orden público para su supresión (Vila, 1991).

La obra se representaba en la plaza del pueblo, totalmente integrada en la escenificación, y dirigidos por el cura había un mínimo de 89 personajes, cifra que sobre el total del pueblo en aquel tiempo suponía el $10 \%$ de la población: la proporción es mucho más alta en cifras reales si tenemos en cuenta que los actores eran sólo hombres — costumbre que se mantuvo en el Rosellón hasta 1888 - (Estos datos nos orientan también hacia la obra anterior de Collell, en que las cotas de participación habían de ser incluso más altas; según mis cálculos, fuese en Galliners o en El Torn, un habitante de cada tres tendría que hacer de actor: por lo que hay que pensar preferentemente en una colaboración comarcal, más allá de los límites del pueblo.)

Por último, uniremos las grandes coordenadas del tema antes de poner punto final con una obra que puede hacer de epígono del género. Esta gran corriente de teatro tradicional, tanto la profana como la religiosa, abocará en el siglo XIX en el drama burgués. Esto quiere decir que entonces ya habrá unos nuevos espectadores, quienes filtrarán el hecho popular a través de la valoración romántica. El drama religioso romántico llegará en 1856 con La Verge de les Mercès de la mano de Manuel Angelon. Sin embargo, este drama estará ya muy lejos de aquel viejo teatro hagiográfico.

Tenemos sin embargo un obra, que en 1871 vuelve a la fuente popular y recurre a los más puros elementos tradicionales. Esto la aleja de obras cultas 
como la barroca de Vicenç Garcia sobre santa Bàrbara. Me refiero a la Venjança del martre de Francesc Xavier Butinyà, autor bañolense, lo cual nos afecta especialmente por ser la comarca que hemos venido tratando. La obra también es conocida como Peça dramàtica de sant Martirià, como se denominaba antes de conocerse su autoría, que revelé en mi tesis doctoral (Barcelona, 1978).

Aparece todavía así y como anónima en la Història de la Literatura Catalana en 11 volúmenes, principal estudio anterior sobre esta obra, y en otras fuentes bibliográficas que lo repiten aún erróneamente. Hasta tal punto se confundió con el género tradicional.

Ahora bien, La venjança del martre, que trata del martirio del patrón de Bañolas, san Martirián, a pesar de responder al auténtico teatro de rancia ascendencia, presenta ya una métrica rica y adaptada a las situaciones y va acompañada de un riguroso compendio histórico a fin de distinguir la verdad de la ficción, como corresponde a un siglo con ansias científicas. Su autor no es un payés con prurito de cultura sino un jesuita, un científico, catedrático de Universidad en Salamanca. Nos hallamos, pues, ante una curiosa obra hagiográfica de la Renaixença. EI P. Butinyà, que había bebido de la fuente secular, la adaptaba a una mentalidad, lengua y técnica renacentistas. Con lo cual sigue la receta de las literaturas clásicas de hacer una obra culta con material tradicional.

Esto probablemente no habría sido obstáculo para que hubiese sido una obra viva para el pueblo. Pero no lo fue, a pesar de tener su divulgación comarcal y ser editada (1871), y por ello no le dedicamos más atención a pesar de su valor literario. Para su verdadera alineación con el género tradicional fallaban ostentosamente dos factores: por un lado, carece del elemento del humor, consustancial como hemos visto en este teatro; y por otro - $y$ he aquí que una vez más se nos pone de manifiesto la importancia de la actividad receptora-, la sociedad burguesa e industrial —como bien anticipaba aquel historiador provenzal - no ofrecía ya el hábitat propio del teatro hagiográfico. Así, aún siendo paradigmática del género, es ya una obra literaria culta y no popular.

\section{BIBLIOGRAFÍA}

Bohigas, P., Notes sobre l'antic teatre català, en Aportació a l'estudi de la literatura catalana, "Biblioteca Abat Oliba", 23, Publicacions de l'Abadia de Montserrat, 1982.

BUtinya, F., La venjança del martre, Barcelona, 1871.

Butinyà, J., Un autor de pagès al segle XVIII: Narcís Collell, "Revista de L'Alguer", $3(1993)$. 
Id., Una comèdia de santa Quitèria del segle XVII, En “Quaderns del Centre d'Estudis Comarcals de Banyoles", en prensa.

Id. (ed.), La venjança del martre de F. Butinyà, Centre d'Estudis Comarcals de Banyoles, en prensa.

Id., Prat, E.; VIla, P., Comèdia de santa Tecla. (Obra hagiográfica del segle XVIII), "Annals. Institut d'Estudis Gironins" XXXII (1993).

CARBonell, J., La literatura catalana durant el periode de transició, del segle XVIII al $X I X$, en Actes del IV Col.loqui Internacional de Llengua i Literatura Catalana, Publicacions de l'Abadia de Montserrat, 1977.

Comas, A., Història de la Literatura Catalana, IV, ed. Ariel, Barcelona, 1972.

Id., Problemàtica de la Decadència, en Actes del V Col.loqui Internacional de Llengua i Literatura Catalana, Publicacions de l'Abadia de Montserrat, 1980.

Id., Estudis de Literatura catalana (segles XVII-XVIII), ed. Curial, Barcelona, 1985.

Constans, L., Dos obras maestras del arte gótico en Bañolas, Barcelona, 1947.

Id., Bañolas, Bañolas, 1951.

Courcelles, D. De, Els cossos dels sants en els càntics catalans del final de l'Edat Mitjana, en Estudis de Literatura Catalana en honor de Josep Romeu i Figueres, I, "Biblioteca Abat Oliva", 44, Publicacions de l'Abadia de Montserrat, 1986.

DÉlÉHAYE, H., Les passions des martyrs et les genres littéraires, Bureaux de la Société des Bollandistes, Bruselas, 1921.

FÀbreGas, X., Història del teatre català, ed. Millà, Barcelona, 1978.

GaRCIa, V., Comèdia famosa gloriosa de la gloriosa verge y màrtir santa Bàrbara, a cargo de À. Massip y F. J. Massip, Barcelona, 1987.

Girbal, E. C., El teatro en Gerona, "Revista de Gerona", 17 (1893).

HEss, R., El drama religioso románico como comedia religiosa y profana (s. XV-XVI), ed. Gredos, Madrid, 1976.

Huerta VIÑas, F., Teatre bíblic, "Els Nostres Clàssics”, ed. Barcino, Barcelona, 1976.

Lascombes, A., De la fonction théâtrale des personnages du mal, en Sixth triennial Colloquium of the International Society for the Study of Medieval Theatre, Lancaster, 1989.

LE Braz, Le théâtre celtique, ed. Slatkine, París-Ginebra, 1981.

Ley, CH. D., El gracioso en el teatro de la Península, Madrid, 1954. 
Martinez Quintanill.a, P., La provincia de Gerona. Datos estadísticos, impr. F. Dorca, Gerona, 1865.

Massip, J. F., Teatre religiós medieval als Països Catalans, ed. 62, Barcelona, 1984.

Id., El teatre de Francesc Vicent Garcia, en El Barroc catalì, ed. Quaderns Crema, Barcelona, 1989.

Massot I Muntaner, J., Notes sobre la supervivència del teatre català antic, "Estudis Romànics”, XI (1962).

Migne, J. P., Dictionnaire des Mystères, Turnholti, 1989.

Milà I Fontanals, M., Orígenes del teatro catalán, en Obras Completas, VI, 1895.

Monsalvatje, F., Nomenclator histórico de las iglesias parroquiales, rurales, santuarios y capillas de la provincia y obispado de Gerona, XVII, Olot, 1910.

Pons, J. S., La littérature catalane en Roussillon au XVII et au XVIII siècles, PrivatDidier, Tolosa, 1929.

Quirante, L., La ciudad en el templo: la consueta de santa Ágata, en Sixth triennial Colloquium of the International Society for the Study of Medieval Theatre. Lancaster, 1989.

Rafanell, A., Rossich, A., El barroc català. Actes de les Jornades celebrades a Girona els dies 17, 18 i 19 de desembre de 1987, a cargo de, ed. Quaderns Crema, Barcelona, 1989.

RIBERA, J., Castellanizaciones y decadencias en las literaturas peninsulares (siglos XVI-XIX), “Revista de Filología Románica", 6 (1989).

RiQuer, I. DE, El juego de la decapitación, en Literatura y fantasía en la Edad Media, Granada, 1989.

Riquer, M. DE, Història de la Literatura Catalana, III, ed. Ariel, Barcelona, 2. ed. 1980.

Romeu I Figueres, J. Teatro hispánico del periodo románico, "Estudis Escènics", IX (1963).

Id., La dramatúrgia catalana medieval: urgència d'una valoració, "Estudis Escènics", III (1958).

Id., Teatre hagiogràfic, 3 vol., "Els Nostres Clàssics", Barcelona, 1957.

Id., Teatre profà, I, "Els Nostres Clàssics”, ed. Barcino, Barcelona, 1962.

Rossich, A., Una poètica del Barroc. El Parnàs català, pr. de M. Prats, Universitat de Girona, 1979.

Id., Francesc Vicent Garcia i el Barroc hispànic, "Els Marges", 31 (1984). 
Id.. La literatura catalana, entre el Barroc i el Romanticisme, "Caplletra", 9 (1990).

Rubió a Balagufr, J., Història de la Literatura catalana, 3 vol.. "Biblioteca Abat Oliba". 23, 35, 51, Publicacions de l'Abadia de Montserrat, 1984-86.

Salvador, V. (coord.), Teletextos, I y II, Universidad de Valencia, 1989-1990.

Serra Campins, A., Notes sobre la tradició oral i l'antic teatre popular, "Randa", XIV (1983).

URkizu, P., Introduction aux farces charivariques basques, en Sixth triennial Colloquium of the International Society for the Study of Medieval Theatre, Lancaster, 1989.

Verdaguer, P., Dues concepcions de l'art.: exemple del teatre nord-català, "Revista de L'Alguer", I (1990).

VILA, P., Teatre català del Rosselló (segles XVII-XIX), ed., Curial, Barcelona, 1989.

Id., L'escenificació del martiri de S. Julià i S. Basilisa, obra dramàtica rossellonessa del segle XIX, "Revista de L'Alguer", 2 (1991).

Id., A propòsit de Bartolomé Palau i la dramatúrgia espanyola del segle XVI a Catalunya, "Estudi General", 11, Girona, 1991.

Id., Prat, E., Entremès del Ball dels ermitans, Banyoles, 1991.

Id., Bruguet, M., Festes públiques i teatre a Girona. Segles XIV-XVIII, Girona, 1983.

Villegias, A. De., La Levenda de Oro, Barcelona, 4. ${ }^{a}$ ed., 1865-66. 